\title{
Preventive Medicine through the Efficiency of Marketing Communication and Promotional Materials
}

\author{
Marinela Filofteia Hostiuc, Gabriel Radu*, Maria Solomon, Victor Lorin Purcarea \\ University of Medicine and Pharmacy "Carol Davila", Romania
}

Copyright $@ 2017$ by authors, all rights reserved. Authors agree that this article remains permanently open access under the terms of the Creative Commons Attribution License 4.0 International License

\begin{abstract}
Health communication and the use of communication strategies aim to inform and to influence general population choices regarding healthcare and quality of life choices. Obesity and overweight status are major contributors to many preventable causes of death. Higher body weight is associated with more death rates. The number of overweight children, adolescents, and adults has risen over the past four decades. Health care programs, by recognizing opportunities to improve communication, assign resources and measure, expand and report health-literacy activities, can succeed in improving the general population health and quality of life.
\end{abstract}

Keywords Marketing Communications, Medicine Prevention, Obesity

\section{Introduction}

Preventive Medicine [1] is defined as all measurements and measures taken by an individual, family, society and the state, with the aim of promoting the prevention of a particular disease and the reduction of their consequences in the general population. There are three different types of preventive medicine (primary, secondary and tertiary) and the main objectives are health promotion and disease prevention programs focusing on keeping the general population healthy.

Primary prevention [2] refers to measuring and lowering the frequency of disease in otherwise healthy persons via the use of disposable medical instruments, information campaigns, educating the population about the ways of disease transmission (e.g. HIV), vaccination.

Secondary prevention [3] is the early detection of disease so as to prevent the onset of complications, which should result in a reduction in prevalence by decreasing the duration of illness and accelerating of the healing.

The tertiary prevention [4] reduces the development and the complications of a certain disease, promoting the adaptation of patient condition of an incurable disease; it aims to soften the impact of an ongoing illness or injury that has lasting effects.

According to the World Health Organization [5], health promotion, the main purpose of the preventive medicine, is "the process of enabling people to increase control over, and to improve, their health. It moves beyond a focus on individual behavior towards a wide range of social and environmental interventions."

Preventive medicine programs are influenced by the social determinants of health. They are defined as being "conditions in the places where people live, learn, work, and play that affect a wide range of health risks and outcomes" according to the CDC (Centers for Disease Control and Prevention) [6], which impact modifiable risk behaviors.

The main social determinants of health are the economic, social, cultural, and political conditions, in which people are born, grow, and live and can alter their health status [7]. There are some adjustable risk behaviors like tobacco use, poor eating habits and lack of physical activity, that contribute to the development of chronic disease.

For improving the health promotion and disease prevention programs, according to the US Department of Health and Human Services [8], the following must be implicated: communication- promotion of the healthy behaviors for the population, education- through courses, trainings, public service announcements so the general population can learn about the risk of different diseases, environment- innovation of structures can make learning about healthy habits more accessible and policy- with the help of organizations or public agencies we can mandate activities to encourage healthy decision.

Communication is, according to the definition given by John J. Burnet [9], "a process by which two or more people try, using symbols, to exert a conscious or unconscious influence on others to satisfy their interests,"

On the other hand, Terence A. Shimp [10], believes that "communication is the process by which ideas are transmitted, and intentions are shared between individuals or organizations and individuals". So the focus is shifted on the 
presence of the groups in communication acting both as transmitters and as receivers of messages. In this situation neither party can assess the complexity of defining communication as a hole.

Michael Ray [11] believes that in marketing, communication "is a mix of four elements (advertising, personal selling, sales promotion and public relations), or explicit messages, designed to evoke certain opinions, feelings or behaviors". Also, he believes that "marketing communication corresponds to a particular situation and is part of the marketing mix alongside product, price and distribution".

Excellent communication is achieved by targeting groups that understand advantages, disadvantages of a society and how it works, what its "rules" are and helps identify the appropriate solutions to inherent problems. Even though having a well-trained staff is crucial, its cultural and educational background is the difference between being able to achieve a short-term goal such as a project, or a long-term goal, a successful public health program. Through guidance, employee performance within a healthcare organization may be improved by successful accomplishment of their given tasks.

Health communication and the use of communication strategies have the aim to inform and influence general population choices. Health care facilities may use communication tools available for material goods: publicity, sales promotion, personal selling and public relations.

Media strategies include the following components in order to transmit the health care message: radio, television, newspaper, flyers, brochures, Internet and social media. With the help of various communication channels, health messages can be transmitted to mass media or to the community. Health communication strategies aim to change people's knowledge, attitudes, and/or behaviors.

Health communication strategies can be efficient if the following components, according with the RHUI Hub [12], are taken in consideration:

- The use of research-based strategies to shape materials and products and selection channels that delivers them to the intended audience.

- Understanding of conventional wisdom, concepts, language, and priorities for different cultural settings and circumstances

- Consideration of health literacy, internet access, media exposure, and cultural competency of target populations.

- Development of materials such as brochures, billboards, newspaper articles, television broadcasts, radio commercials, public service announcements, newsletters, pamphlets, videos, digital tools, case studies, group discussions, health fairs, field trips, and workbooks among others media outlets.

Health care organizations facilitate enrolment and exploration of patients and their families within their environment to promote understanding and use of health information and services towards improvement of health and quality of life.

There is increased evidence that people with limited health literacy are more likely to have less health-related knowledge, lower self-efficacy for self-care, worse control of their medical conditions, and increased rates of hospitalization and premature death [13]. Health education represents not only an individual's skills but also the burdens, complexities, and culture of the health care system [14].

Also, research has revealed that specific strategies delivered by health care programs to address health training may improve patient understanding, self-efficacy and self-care behaviors, with important clinical outcomes [15].

The Office of Disease Prevention and Health Promotion [16] recommends respecting the following principles so that a health communication program has a significant impact

- Accuracy: The content of the program must be accurate and without errors of fact, interpretation, or judgment.

- Availability: The matter of the health program must be delivered or placed where the target population can access it. Placement varies according to the audience, message complexity, and purpose, ranging from interpersonal and social networks to billboards and mass transit signs to prime-time TV or radio, to public kiosks (print or electronic), to the Internet.

- Balance: The health program must present the benefits and risks of potential actions or recognize different and valid perspectives on the issue.

- Consistency: The content must remain persistent over time and must also be consistent with information from other sources

- Cultural Competence: The design, implementation, and evaluation process that accounts for the health project must be selected for population groups (for example, ethnic, racial, and linguistic) and also must take in consideration the educational levels and disability.

- Evidence-based: Relevant scientific evidence that has undergone comprehensive review and rigorous analysis to formulate practice guidelines, performance measures, review criteria, and technology assessments for health applications.

- Reach: The matter must reach to the largest possible number of people in the target population.

- Reliability: The source of the content must be credible and the content itself must be kept up to date.

- Repetition: The delivery of the health care program must be continued or repeated over time.

\section{Material and Method}

Obesity and overweight status are major contributors to many preventable causes of death. Higher body weight is associated with more death rates. The number of overweight children, adolescents, and adults has risen over the past four decades.

Experts estimate that by 2030 half of all Americans will be obese if the current path continues [17]. 
Obesity rises the risk of many serious health conditions[18], [19] like: coronary heart disease, stroke, and high blood pressure, type 2 diabetes, cancer endometrial, breast and colon cancer), gallbladder disease, sleep apnea and respiratory problems, osteoarthritis, reproductive health complications (infertility) and depression.

Unfortunately obesity and the associated health problems demands considerable economic impact on the individual patient and the U.S. health care system. [20]. The economic impact its due to medical costs such as preventive, diagnostic and treatment services related to obesity and resulting conditions, and also because of costs resulting from decreased productivity, disability, absenteeism, and loss of future income due to premature death. [21], [22], [23].

According to the National Health and Nutrition Examination Survey in United States of America, the prevalence of obesity is over $36 \%$ in adults and $17 \%$ in youth. The prevalence of obesity is higher in women (38.3\%) than in men (34.3\%). Among all youth, no difference is seen by sex. The prevalence of obesity was higher among middle-aged (40.2\%) and older adults (37.0\%) than younger adults (32.3\%).

Adult obesity rates now exceed 35 percent in four states, 30 percent in 25 states and are above 20 percent in all states. Louisiana has the highest adult obesity rate at 36.2 percent and Colorado has the lowest at 20.2 percent. [24]. (see Figure 1).

In Romania over $56 \%$ men are overweight and obese, while among women $48 \%$ face this condition. $18 \%$ of young people (15-24 years old) are overweight. The most advanced forms of obesity occur in people aged 45-64 years (25.2\%);

\section{Percent of obese adults (Body Mass Index of $30+$ )}

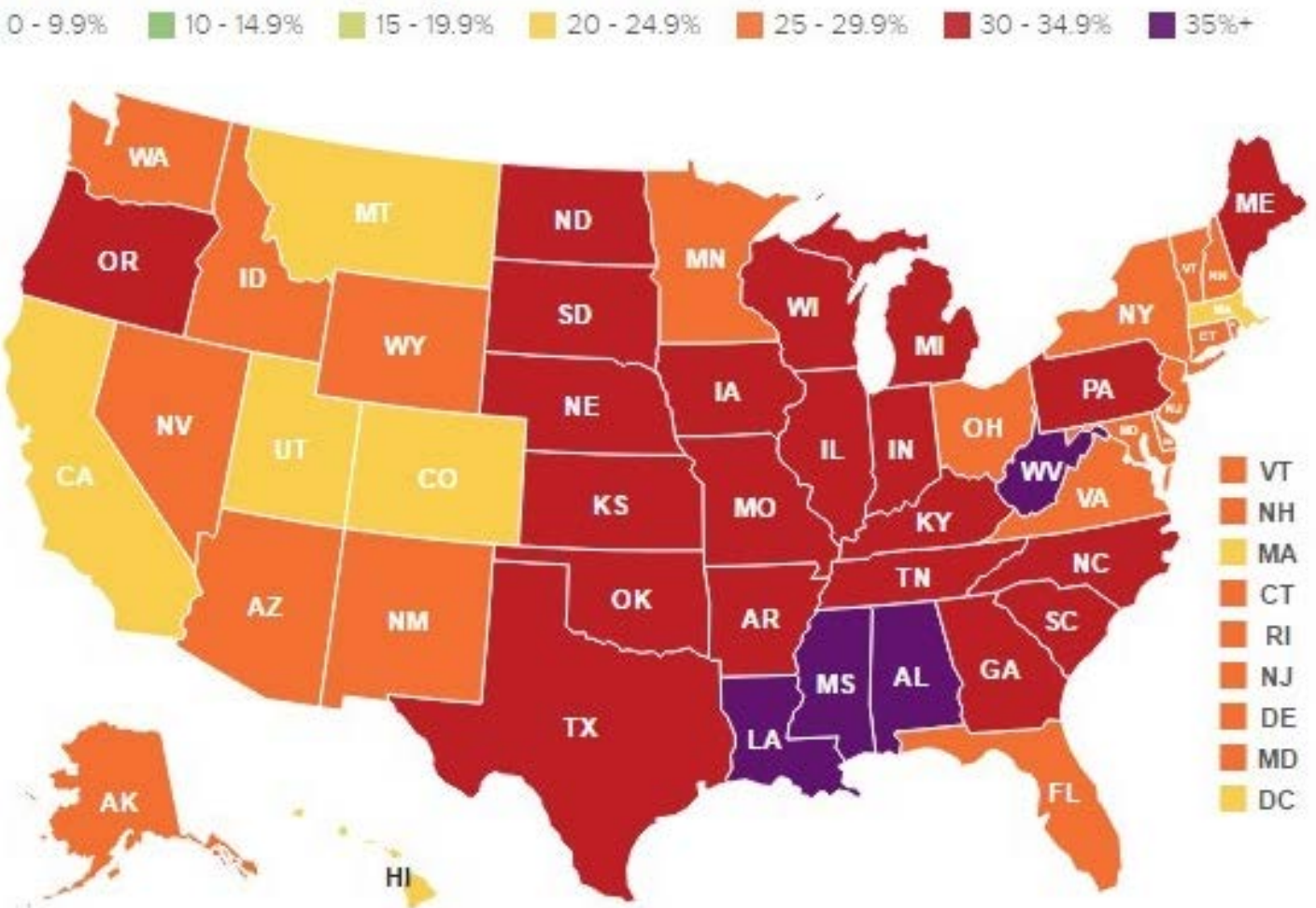

Figure 1. The Adult Obesity Rates in USA 


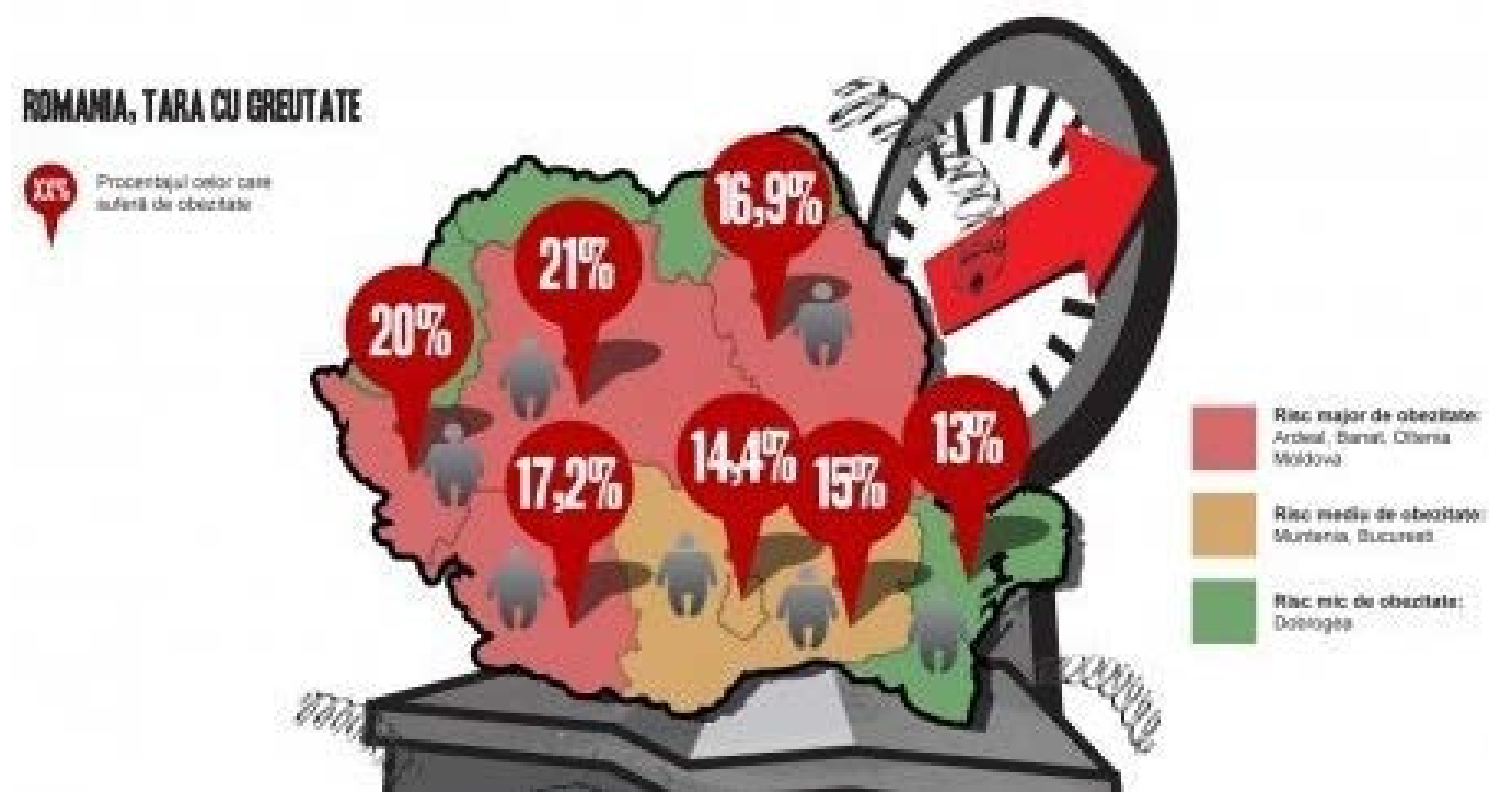

Figure 2. Adult Obesity Rates in Romania

Among the regions of Romania, Transylvania is confronted with the problem of obesity, being in the top of the affected areas. Approximately $21 \%$ of respondents living in Transylvania and Banat are suffering from obesity. The next place, with $17.2 \%$ obese people from the total population, is Oltenia. [25]. (see Figure 2).

In the USA, the Health Equity Resource Toolkit (see Figure 3) is used for state practitioners addressing obesity disparities and was prepared by the Center for Disease Control and Prevention (CDC), National Center for Chronic Disease Prevention and Health Promotion, Division of Nutrition, Physical Activity and Obesity. This toolkit helps state health departments and partners work with communities to reduce obesity in populations experiencing health problems. It helps users learn how changes in policy, health systems and environment can reduce obesity disparities and achieve a higher health status in the general population.

The toolkit[26] (see Figure 4) presents approaches to gather key steps from several types of planning to integrate in the health care program and change models into a simple six-step planning process.

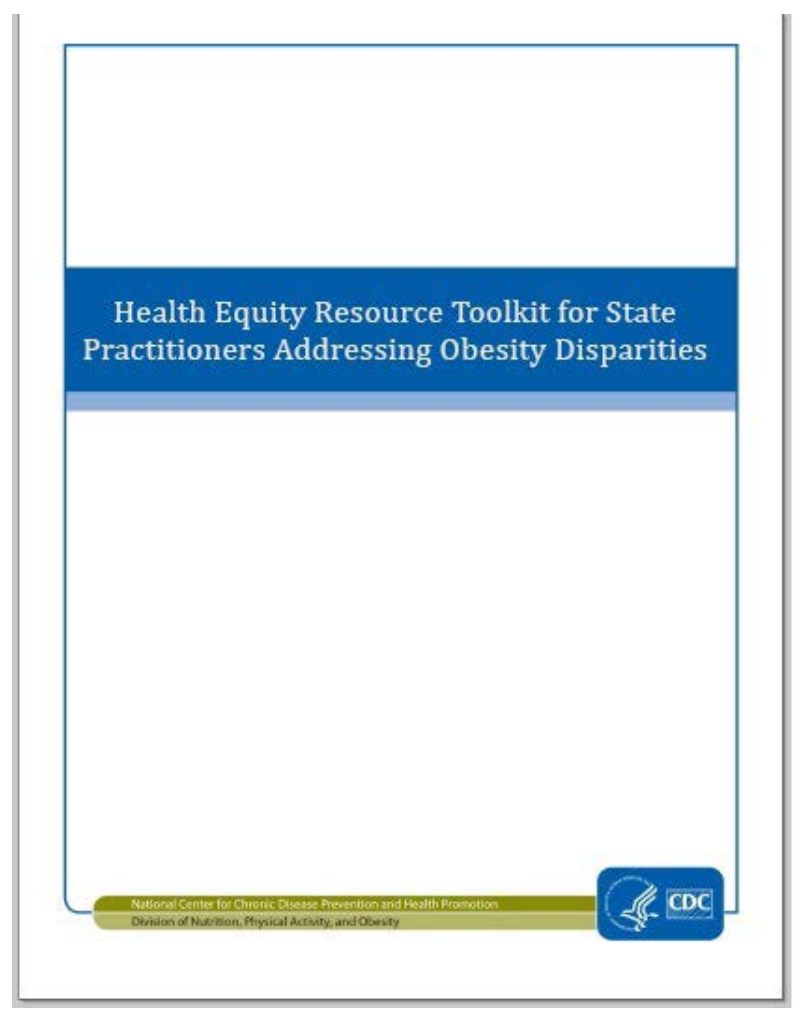

Figure 3. The Health Equity Resource Toolkit for state practitioners addressing obesity disparities 


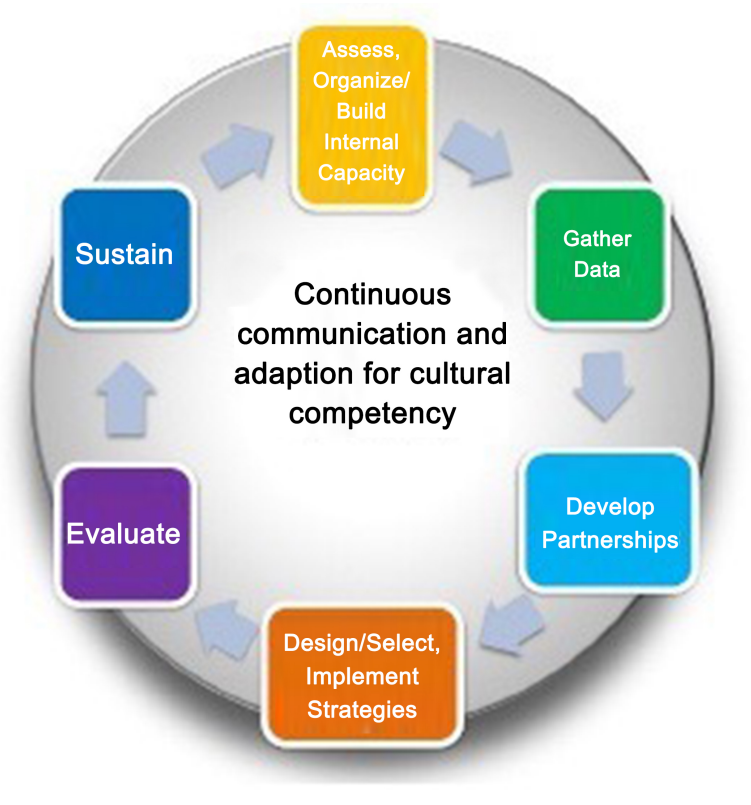

Figure 4. Health Equity Resource Toolkit prepared by CDC

The six steps included in the health care program regarding obesity [27] are:

1. Program assessment and capacity building- using Health Equity Impact Assessments and SWOT (Strengths, Weaknesses, Opportunities and Threats) can facilitate analyses for an effective obesity health equity initiative.

2. Gathering and using data to identify and monitor obesity disparities through a health equity lens- community level data can provide direction as to how and where to concentrate obesity prevention efforts to achieve health equity.

3. Applying a health equity lens to the design and selection of strategies In this section, a series of steps is described through which partners are brought together to discuss data, prioritize an evidence-informed policy or environmental approach, assess the health impact of the potential approach.

4. Developing multi-sector and non-traditional partnerships. Partnerships can bring a number of assets to an initiative, including shared resources, increased power and strength, a greater likelihood of initiative sustainability, flexibility to adapt, and program champions

5. Monitoring progress can guide program efforts and help one quickly identify unintended negative consequences, evaluate the measure of extent to which a program had the desired effect

6. Policy and environmental changes, the last step of the $\mathrm{kit}_{2}$ are often the most sustained approaches to improving public health.

This document [28] (see Figure 3) was created to provide examples of strategies and surveillance data which can be used to inform obesity prevention initiatives.

In Romania, the Prevention Guide- Healthy Lifestyle and Other Preventive Prevention Actions for Non-Communicable Diseases in Primary Healthcare (see
Figure 5)- is an instrument, dedicated primarily to primary care professionals, family doctors and nurses, with the intent of familiarizing them with concepts in the modern fields of preventive medicine and enabling them to teach their patients about the correct way of fighting obesity.

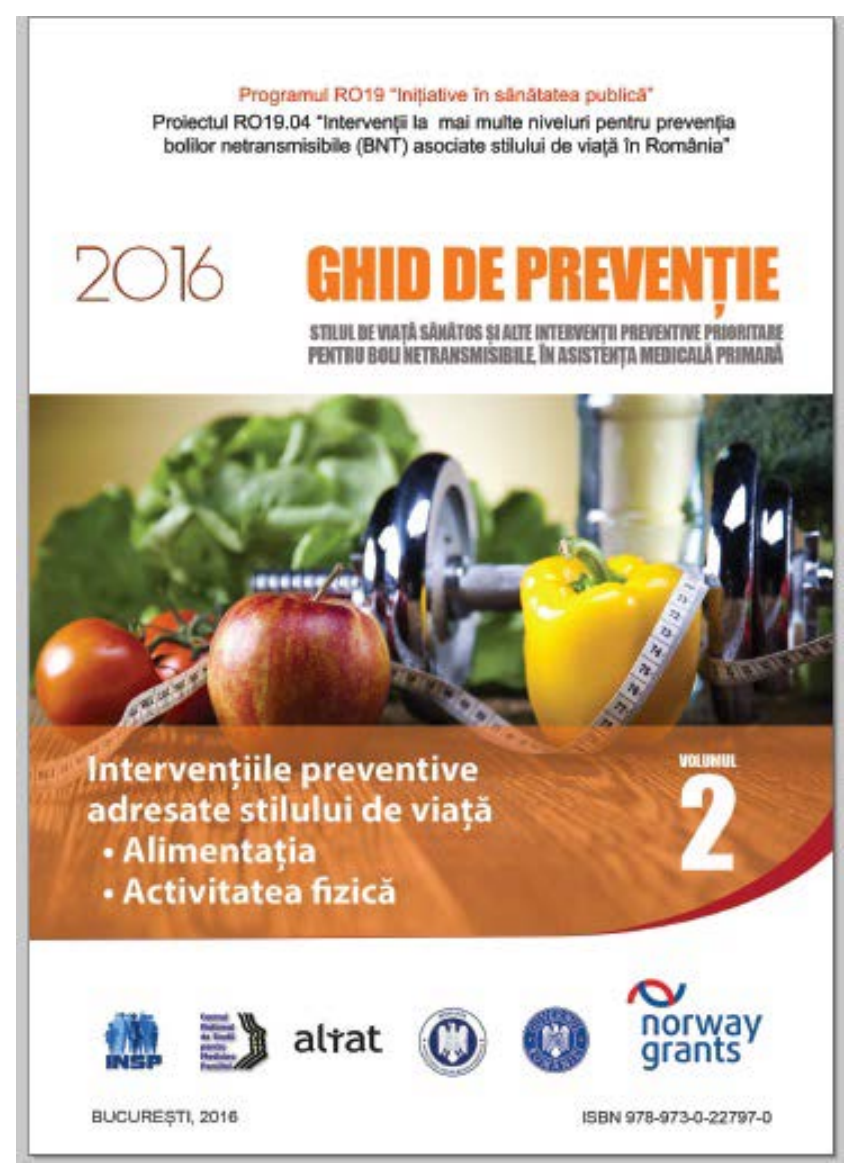

Figure 5. The Prevention Guide- Healthy Lifestyle and Other Preventive Prevention

This is an educational vehicle designed to raise the awareness of the general public and to create a general platform of understanding, without which the battle for preserving / regaining health, can only be considered a struggle without success [29].

Prevention Guide has seven volumes and its second volume (Lifestyle Prevention Interventions: Nutrition, Physical Activity) brings us closer to the realm of international disputes in population refrigerator and to the universal consensus on the need for more movement.

In the guide are answers for the next questions: WHY, WHAT and especially WHAT to eat to keep us healthy? What are some of the most common mistakes? Is there a single method to reduce many of them? WHY, WHAT and HOW much physical activity to undertake? In the guide numerous recommendations on what it means to have a pro-health behavior, diet and a healthy level of physical activity.

In order to see the effectiveness of this guide in Romania, we employed a study that included two types of surveys 
containing questions addressed to patients before and after explaining and showing basic rules for preventive interventions to lifestyle: nutrition and physical activity, which is the base of eradication of obesity, that were distributed in a family physician office.

Before explaining the principles regarding the alimentation and physical activities, we selected patients from a family physician office and gave them a questionnaire asking questions about their contact with prevention medicine about obesity and their knowledge regarding the subject.

The questionnaire includes four demographic variables and other three questions related to the impact of general advertising messages about preventive obesity. Demographic variables are age, education, marital status and the presence of children.

Demography of age divides into three segments following groups: 20-40 years, $40-60$ years and over 60 years (Table 1 ). 43 people in the study were aged between $20-40$ years.

Table 1. Age of the people participating in the study

\begin{tabular}{|c|c|c|c|}
\hline Age & $20-40$ years & $40-60$ years & $>60$ years \\
\hline & 43 & 3 & 0 \\
\hline
\end{tabular}

Table 2. Type of education of the people involved in the study

\begin{tabular}{|c|c|c|c|c|}
\hline $\begin{array}{c}\text { Type of } \\
\text { education }\end{array}$ & $\begin{array}{c}\text { Secondary } \\
\text { education }\end{array}$ & $\begin{array}{c}\text { High } \\
\text { school }\end{array}$ & Undergraduate & Graduate \\
\hline & 3 & 13 & 20 & 10 \\
\hline
\end{tabular}

Education refers to secondary education, high-school, undergraduate and graduate levels respectively (Table 2). In the study 20 people graduated.

Table 3. Marital Status of the people in the study

\begin{tabular}{|c|c|c|c|c|}
\hline Status & Unmarried & Married & Divorced & Widowed \\
\hline & 17 & 21 & 5 & 3 \\
\hline
\end{tabular}

Table 4. Number of children of the people in the study

\begin{tabular}{|c|c|c|c|c|c|}
\hline $\begin{array}{c}\text { Number of } \\
\text { children }\end{array}$ & 0 & 1 & 2 & 3 & $\begin{array}{c}\text { More } \\
\text { than } 3\end{array}$ \\
\hline & 22 & 13 & 6 & 3 & 2 \\
\hline
\end{tabular}

Marital status included unmarried, married, divorced and widowed. 21 people were married.

The number of children could be $0,1,2,3$ or more than 3 . Most of the people interviewed didn't have children.

When asked "How often have you been exposed to promotional messages on preventive medicine?" most people participating (18) said they have exposed to more than five messages per month on preventive medicine. (See Figure 6)

26 out of 46 people said that sometimes are aware of these messages.

12 people have stated that they sometimes ignore other relevant messages together with messages of prevention medicine. (see Figure 7)

In several meetings with the same patients from the family physician office, health care professionals (including doctors, nurses and nutritionists) explained general aspects and particularities of nutrition and physical activity.

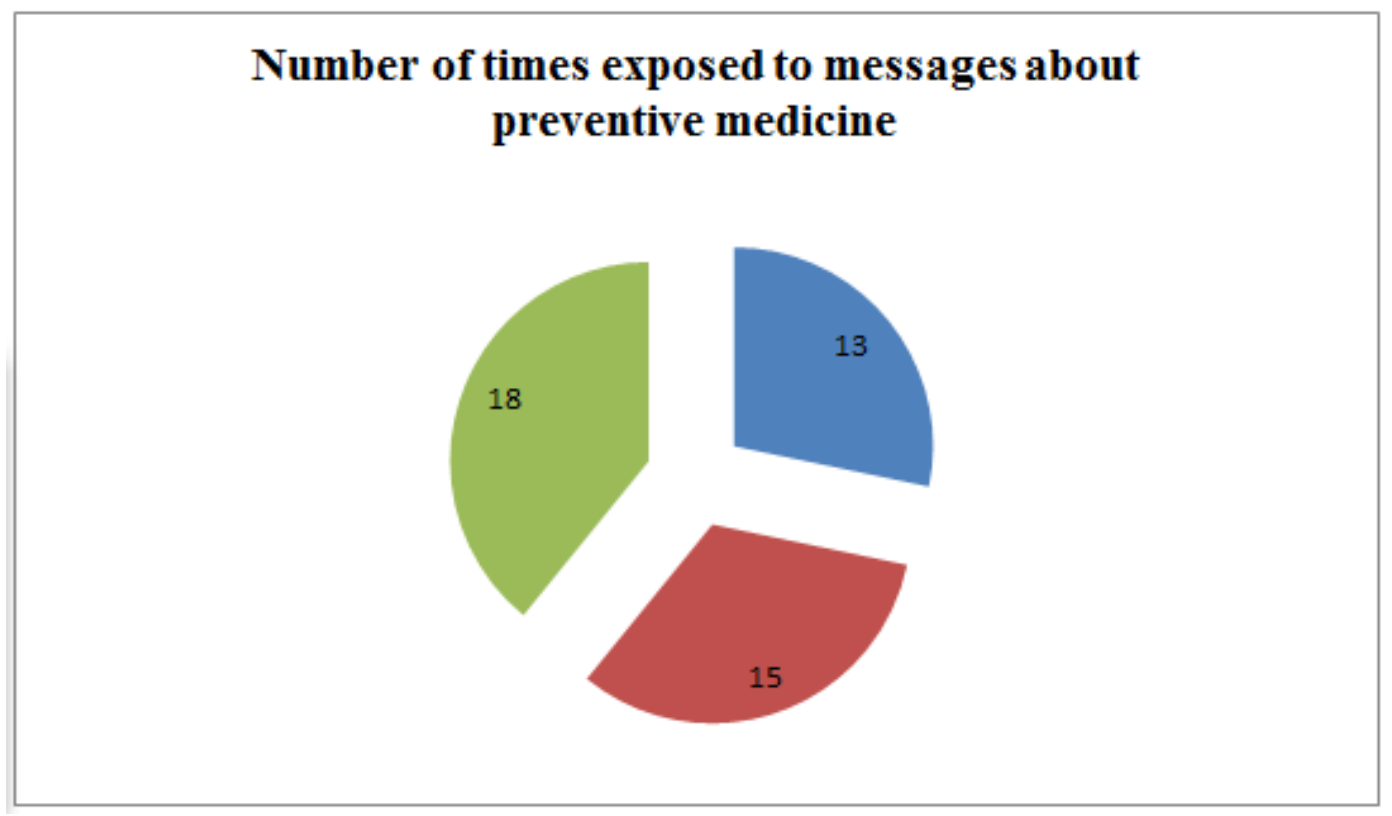

Figure 6. The answer for the question: "How often have you been exposed to promotional messages on preventive medicine?” The answers can be: once per month, between 2-5 per months or over 5 per month. 


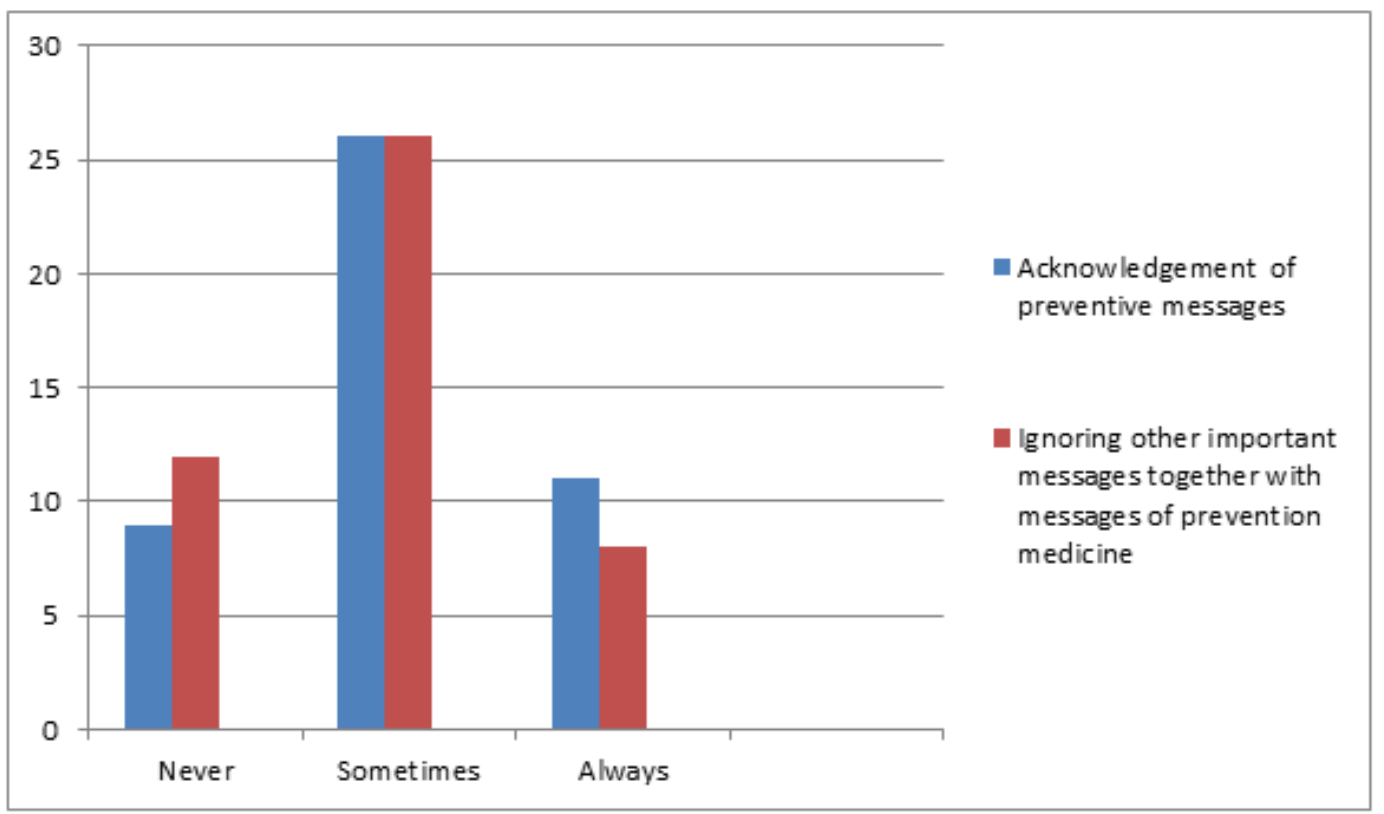

Figure 7. Answers for two questions in comparison: "When do you acknowledge these promotional messages on preventive medicine?” and "How many times did you ignore other important messages together with messages of prevention medicine?’. The possible answers are: never, sometimes or always.
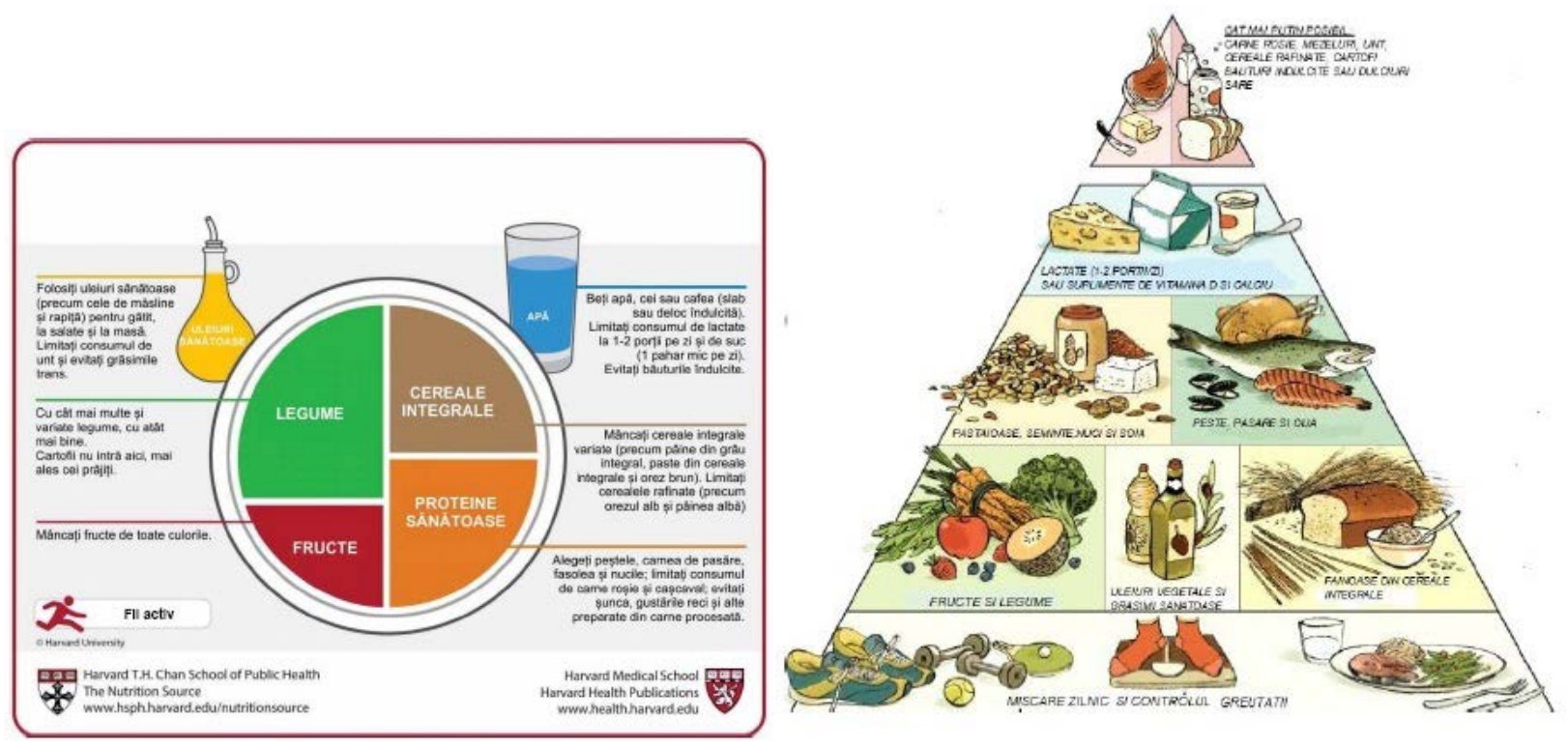

Figure 8. Examples of promo materials regarding the alimentation show to the patients 


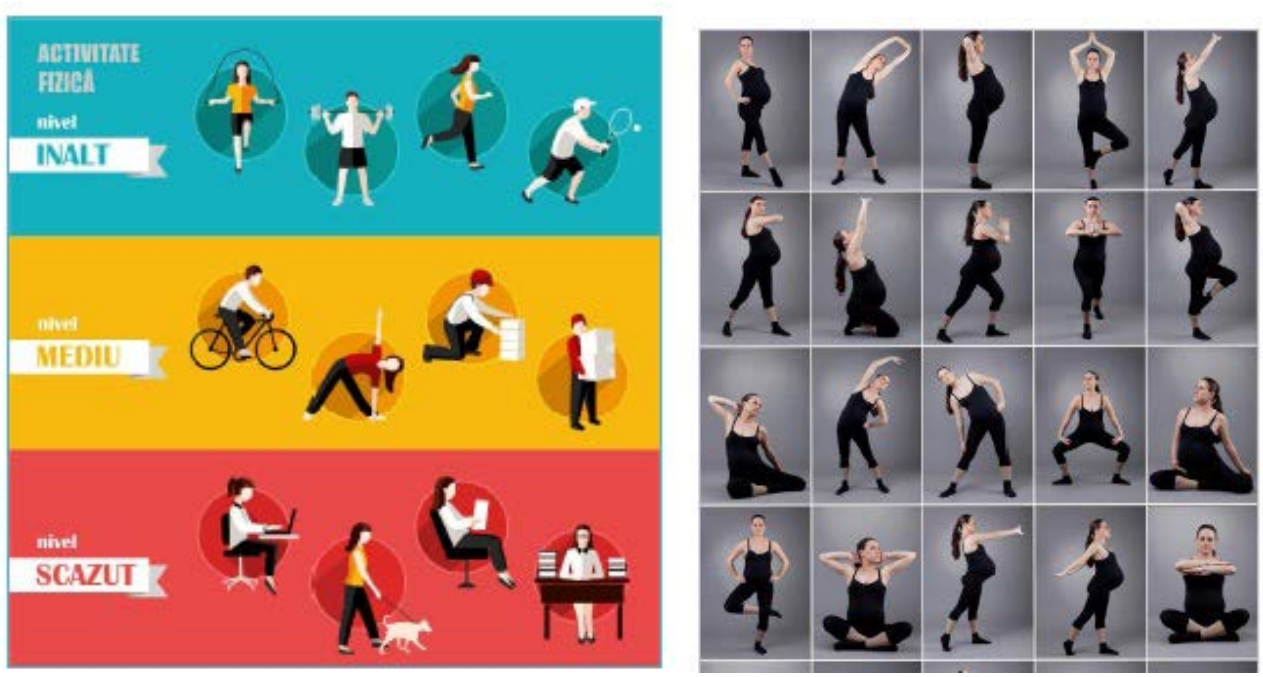

Figure 9. Examples of physical activities

With the help of various promo materials (see Figure 8 and Figure 9) which consisted of banners, posters that ranged from an A5 sized brochure to wall-sized stands, movies and giving practical advices, the health care staff explained the importance of alimentation and having physical activity including during pregnancy.

The second questionnaire was given out to the same patients from the family physician office, after explaining basic and specific principles in alimentation and physical activity (according to the Prevention Guide- Healthy Lifestyle and Other Preventive Prevention Actions for Non-Communicable Diseases in Primary Healthcare used in Romania), the key of decreasing the percentage of obesity in Romania; it contained questions that emphasized the impact of these promo materials.

The second questionnaire included three questions about the effects of these messages about preventive medicine of obesity.

The first question used is about efficiencies of the strategies used: "Do you consider this method useless?" 20 patients think this method of promotion is efficacious and they liked the practical part of knowing the advantages about losing weight and maintaining their health.

The second question refers to the commitment of the patients for respecting the advices received after the education training: "Are you motivated to respect the advices received?” and 27 patients said yes. (see Figure 10)

And the third question is related to the reasons why patients couldn't respect the advices received: "What are the reasons that prevent you from following the advice you received?” and most of the participants (28) said it is because of difficulty to adhere to said advice. (Figure 11)

\section{Conclusions}

If we respect and take in consideration health communication strategies recommended by RHUI Hub [30], we can be efficient regarding the promotion of the preventive healthcare. In the study we used research-based strategies to set up the proper medical material regarding the obesity problem. The main problem in obesity is lack of psychical activity and bad choices regarding alimentation.

First step was showing evidence that losing weight can be effective in reduction the risk in cardiovascular diseases, cancer and neuropsychiatric diseases. The second step was to evaluate the eating behavior.

The next step consisted of discussions and training about recommended eating habits including the motivational interview, detailed recommendations on food groups (cereals, vegetables and fruits, milk and food products, protein foods, fats and water),suggestions on foods to be consumed in very small or occasional quantities (fat, salt, sugar, alcohol) and advices regarding food behaviors (breakfast, snacks, frequency of meals). This was possible with the help of various promo materials (see Figure 8 and Figure 9) which consisted of banners, posters that ranged from an A5 sized brochure to wall-sized stands, movies and handing practical advices.

All this knowledge was explained according to the age, level of education and social status. For undertaking this entire concept, we took in consideration the conventional wisdom, concepts, language, and priorities for different social classes.

Another consideration in training the patient, was the health literacy, internet access, media exposure, and cultural competency of them because they can be influenced by the same channels of promotion that convey a totally opposite message to that proposed by us.

National Action Plan to Improve Health Literacy wants to "promote changes in the health care delivery system that improves health information, communication, informed decision-making, and access to health services" [31]. This purpose requires health care programs to become easier to go through. Health care programs, by recognizing opportunities to improve communication, assign resources and measure, expand and report health-literacy activities, can succeed in improving the general population health and quality of life. 


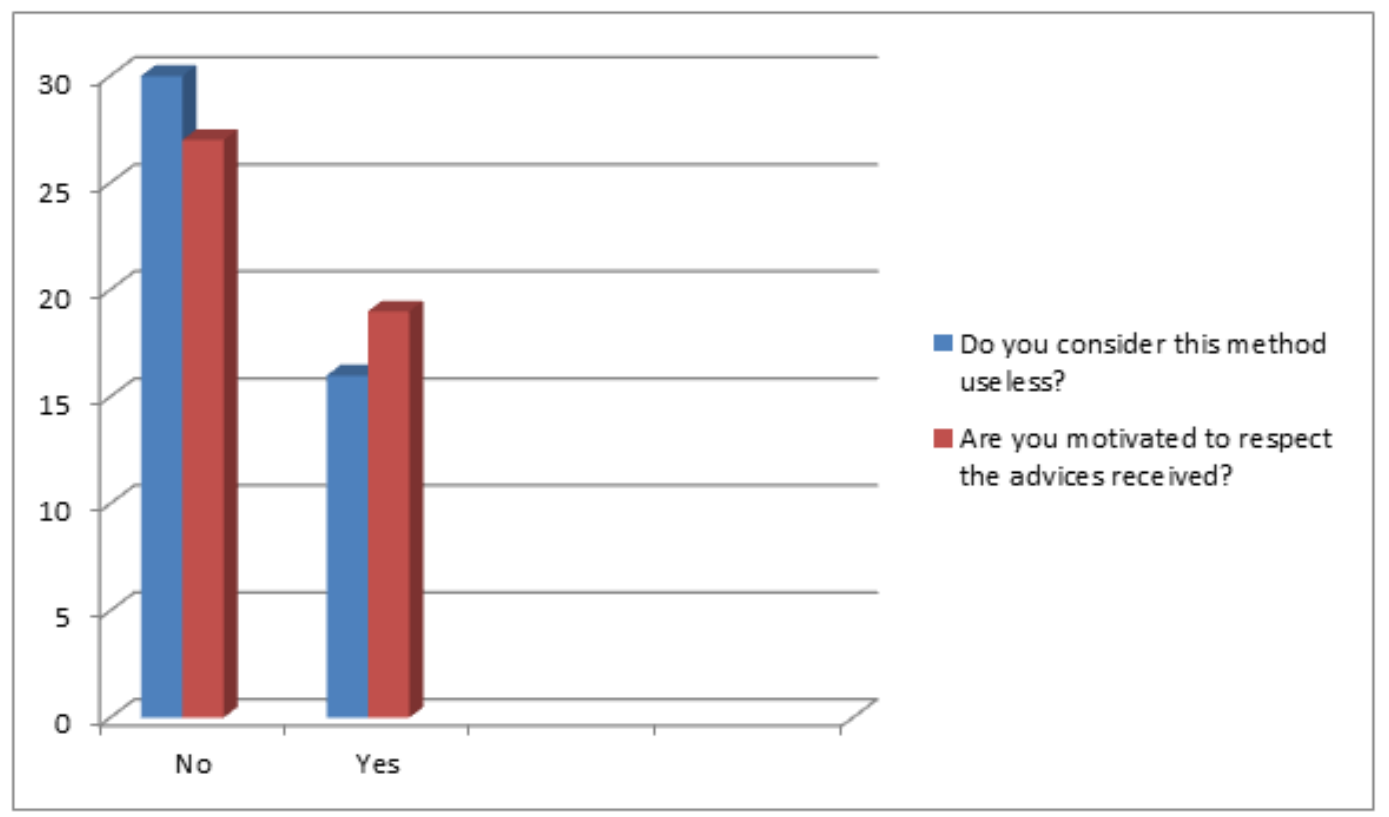

Figure 10. Answers for two questions in comparison: "Do you consider this method useless?" and "Are you motivated to respect the advices received?”.

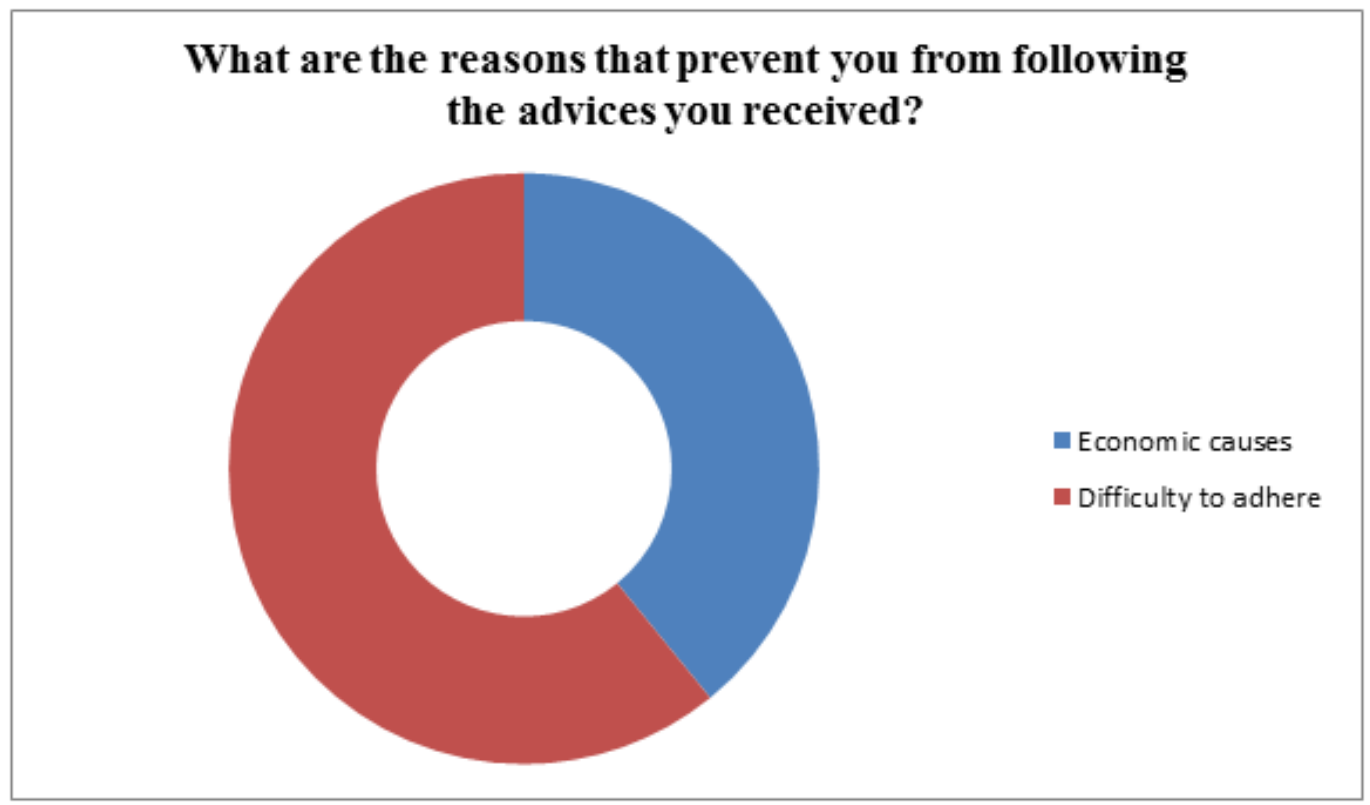

Figure 11. Answer for the question: "What are the reasons that prevent you from following the advices you received?"

In US there are many programs like: Behavioral Risk Factor Surveillance System (BRFSS), National Health and Nutrition Examination Survey (NHANES), Youth Risk Behavior Surveillance System (YRBS), National Health Interview Survey (NHIS) that deal with healthcare regarding nutrition, physical activity and obesity and their main object is to improve health care levels of the general population.

In Romania there is a project named "Multi-level interventions for the prevention of non-transmissible diseases (NTDs) associated with lifestyle in Romania", developed under the Program 19 "Public Health Initiative". This project wants to improve the capacity to effectively implement prevention interventions addressed to major lifestyle risk factors (diet, physical activity, alcohol and tobacco consumption) at primary health care level.

There is a lack of adherence of the patients (28 patients in our study) so some general strategies must be taken in consideration to enhance the quality of health communication. Collaborations between government agencies and technology corporations is an option for adherence improvement and there is room for the canals of communication to be improved (Internet, phone messages, Social media)

People with marginal health literacy skills can improve if health information is written at their level of comfort. Health literacy programs targeting their skill improvement should 
be organized.

Another option is setting up training centers that prepare health communication professionals and health professionals with good communication skills. Serving an educational purpose, these centers should be equipped with health communication and media technologies like media labs, conference rooms etc. They should offer continuous education and distance learning courses. Amongst other purposes, they would serve the mission of "(1) promoting the adoption of health communication theories and practices in health care, disease prevention, and health promotion initiatives, (2) developing and disseminating quality standards, (3) coordinating initiatives to develop a consensus research agenda, (4) developing systems to identify and assess health communication research, (5) evaluating communication strategies, messages, materials, and resources, (6) fostering networking and collaboration among health communicators, health educators, and other health professionals, (7) promoting health communication skills training for health professionals, and (8) promoting research and dissemination activities among specific population groups." [32]

In recent years, a large series of tools and publications have been developed by various agencies such as the Center for Global Health Communication and Marketing to provide health communication training to healthcare workers.

Another important aspect of regarding preventive medicine is identifying target audiences. There are two kinds of target audiences, namely the primary target whose behavior is to be influenced directly and the secondary target that can influence the primary target (e.g. a family member who makes decisions regarding the household or health workers with whom the primary audience comes into contact [33].)

\section{Acknowledgements}

We are very grateful to experts for their appropriate and constructive suggestions to improve this template.

\section{REFERENCES}

[1] Minca, Dana, G. Marcu, Grigorie, M( 2005) “Sănătate publica si management sanitar.” Note de curs pentru invatamantul postuniversitar Editura Universitara “Carol Davila” Bucharest

[2] Minca, Dana,G. Marcu, Grigorie, M( 2005) “Sănătate publica si management sanitar.” Note de curs pentru invatamantul postuniversitar Editura Universitara “Carol Davila” Bucharest

[3] Minca, Dana,G. Marcu, Grigorie, M( 2005) “Sănătate publica si management sanitar.” Note de curs pentru invatamantul postuniversitar Editura Universitara “Carol Davila” Bucharest

[4] https://www.iwh.on.ca/wrmb/primary-secondary-and-tertiaryprevention
[5] http://www.who.int/topics/health_promotion/en/

[6] https://www.cdc.gov/socialdeterminants/

[7] https://www.cdc.gov/socialdeterminants/

[8] https://www.ruralhealthinfo.org/community-health/health-pro motion/1/definition

[9] Burnett, John, J.( 1988, ) "Promotion Management. A Strategic Approach”, ediția a II a, West Publishing Company.

[10] Shimp, Terence, (1997) “Advertising, Promotion and Supplemental Aspects of Mass Communication”, Harcourt Brace College Publishers.

[11] Ray, Michael, L. - “Advertising and Communication Management”, Prentice- Hall

[12] https://www.ruralhealthinfo.org/community-health/health-pro motion/2/strategies/health-communication

[13] Berkman, N., S. L. Sheridan, K. E. Donahue, D. J. Halpern and K. Crotty, "Low health literacy and health outcomes: An updated systematic review". Annals of Internal Medicine, 2011. 155(2): p. 97-107

[14] Brach, C., D. Keller, L. M. Hernandez, C. Baur, R. Parker, B. Dreyer, P. Schyve, A. J. Lemerise, and D. Schillinger, “Ten attributes of health literate health care organizations. Discussion paper”. Washington, DC: Institute of Medicine, 2012.

[15] Berkman, N., S. L. Sheridan, K. E. Donahue, et al., "Health literacy interventions and outcomes: An updated systematic review. Evidence report/technology assessment (full report)”. Rockville, MD: Agency for Health Care Policy and Research, 2011, p. 1-941

[16] U. S. Department of Health and Human Services, National action plan to improve health literacy. Washington, DC: Department of Health and Human Services, 2010.

[17] Wang, Y.C., McPerson, K., Marsh, T., Gortmaker, S.L., \& Brown, M. (2011). "Health and economic burden of the projected obesity trends in the USA and the UK". Lancet, 378: 815-825.

[18] CDC. (2011). “Obesity and overweight: Health consequences".

[19] http://www.cdc.gov/obesity/causes/health.html.

[20] U.S. Department of Health and Human Services. The Surgeon General's call to action to prevent and decrease overweight and obesity. [Rockville, MD]: U.S. Department of Health and Human Services, Public Health Service, Office of the Surgeon General 2011

[21] Wolf, A. (1998). "What is the economic case for treating obesity? Obesity Research”, 6(suppl.): 2S-7S.

[22] Wolf, A.M. \& Colditz, G.A. (1998). "Current estimates of the economic cost of obesity in the United States. Obesity Research”, 6(2): 97-106.

[23] Wolf, A.M. (2002). "Economic outcomes of the obese patient. Obesity Research”, 10, 58S-62S.

[24] http://stateofobesity.org/adult-obesity/

[25] http://www.ponderas.ro/studiu-ponderas-romanii-poarta-cu-ei 
-200-000-de-tone-de-exces-ponderal/

[26] https://www.cdc.gov/obesity/downloads/CDCHealthEquityO besityToolkit508.pdf

[27] https://www.cdc.gov/obesity/downloads/CDCHealthEquityO besityToolkit508.pdf

[28] https://www.cdc.gov/obesity/downloads/CDCHealthEquityO besityToolkit508.pdf

[29] http://cnsmf.ro/ghid-de-preventie-2016/
[30] https://www.ruralhealthinfo.org/community-health/health-pro motion/2/strategies/health-communication

[31] "11 Health Communication." Healthy People 2010. Office of Disease Prevention and Health Promotion. 15 Jun 2009

[32] "11 Health Communication." Healthy People 2010. Office of Disease Prevention and Health Promotion. 15 Jun 2009.

[33] A Guide to Adapting, Developing and Producing Effective Radio Spots." Mar 2005 Web.23 Jun 2009 